\title{
A RECORD OF PLANKTON ON THE ECHO-SOUNDER
}

\author{
By D. H. Cushing and I. D. Richardson \\ Fisheries Laboratory, Lowestoft
}

(Text-figs. I-3)

A number of records from echo-sounders have been loosely attributed to the presence of plankton. Only two records have been adequately identified as having been produced by plankton; first, the traces of fish larvae, or shallow scattering layers (Burd \& Lee, I95I); and secondly, the echo layer, at the depth of the temperature discontinuity or thermocline, which is sometimes associated with plankton animals or plants (Cushing, Lee \& Richardson, in press). A third type of record, that from the 'deep scattering layer', has been associated with the presence of euphausiids (Hersey \& Moore, I948; Moore, I950; Boden, I950): an equally plausible association with the presence of fish has been made by Marshall (I95I), Tucker (I95I) and Hersey \& Backus (I954). A fourth type of echo record, a 'noisy' record, will be described and will show that it is probably attributable to plankton organisms, consisting, in one instance, of euphausiids.

\section{Material AND Method}

During the work to be described the amplifier was kept at known settings, engines had no effect on our echo-sounders and we carried out most of our work in flat calm weather. We sought to identify a factor in 'water noise' by studying the plankton content of the water, at the time when records of noise were being made.

There are three groups of observations, the first in Windermere, followed by two in the North Sea.

\section{RESUlTS AT WINDERMERE}

When we were working on Windermere, the lake was flat and calm. During the daytime, noise appeared suddenly at a high level of amplification, as a black band right across the paper. On one night, however, at a lower level of amplification, noise appeared diffusely from the transmission mark downwards, rather as it does in the sea. But the diffuseness faded with depth, which was not characteristic of noise traces that had been taken at sea. The actual trace is shown in Fig. I. 
Because the diffuse noisy trace that faded with depth was only found at night, it was thought to be associated with the presence of plankton animals that had migrated to the surface at night. The phytoplankton makes no such migration, and although present in the lake in dense numbers, was consequently disregarded.

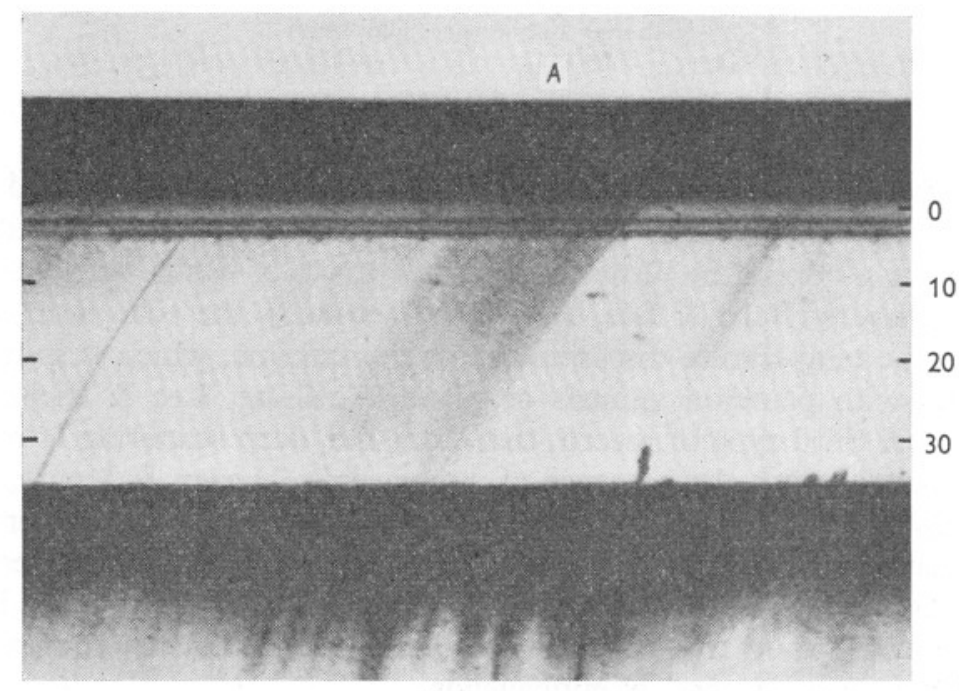

Fig. I. The 'noisy' trace at night in Windermere. Depth in metres shown on right. The diffuse shadow at $\mathrm{A}$, which appeared when the gain control was turned up, is the noisy trace.

Table I. Abundance at night of Diaptomus gracilis Sars., and DAPHNIA HYALINA LEYDIG

(Expressed as number per 5 1. of water at Station RNB 5.)

$\begin{array}{cccc}\text { Depth (m) } & \text { Diaptomus gracilis } & \text { Daphnia hyalina } & \text { Total } \\ \text { O } & \text { I3 } & \text { I } & \text { I32 } \\ 5 & 47 & 2 \text { I } & 68 \\ \text { I2 } & 3 \text { I } & 2 & 33 \\ \text { I6 } & 6 & 3 & 9 \\ 25 & - & 2 & 2\end{array}$

When the diffuse trace was observed, water samples were immediately taken with a 51 . Rodhe bottle at 0,5, I2, I6 and $25 \mathrm{~m}$. The depths were chosen according to the appearance of the trace, the record having faded at $16 \mathrm{~m}$. The counts of plankton animals are given in Table I.

During the daytime, samples were taken chiefly from the depths of the thermocline, at about $10 \mathrm{~m}$. When the animals were concentrated near the thermocline, their numbers reached $28 / 1$. and a trace was recorded at that 
depth. When the animals were not concentrated at the thermocline, their numbers at 0,5 , Io and I2 m were not greater than 2 or $4 / 1$.

There are three points of evidence associating this trace with the presence of plankton animals. First, the fact that it appeared only at night, when the animals had migrated to the surface. Secondly, the trace faded at $16 \mathrm{~m}$ in depth, which is the lower limit to the distribution in depth of the animals; however, if the animals were uniformly distributed, the trace would be of this character because of the dissipation of transmitted energy with depth and the fading at $16 \mathrm{~m}$ could be a coincidence. Lastly, the density of animals that presumably produced the trace, when diffusely spread at the surface, was the same as the density that produced an echo when packed against the thermocline at $10 \mathrm{~m}$, i.e. $28 / 1$. (Cushing et al. in press).

\section{RESUlTS FROM THE NORTH SEA}

In May and June 1953 two gears were being tested, in the North Sea, off North Shields. The first was an echo-sounder, with oscillators mounted on the keel to transmit horizontally. The second was a high-speed plankton net, which was being towed just below the surface.

The horizontal echo-sounder-pulse length, I ms (millisecond)-which was a development project of Messrs Kelvin and Hughes Ltd., had two ranges, 150 and $1500 \mathrm{fm}$ (274 and $2742 \mathrm{~m}$ ); the gain control of the amplifier could be conveniently divided into six points, dividing the degree of amplification into seven levels, $0, \frac{1}{6}, \frac{1}{3}, \frac{1}{2}, \frac{2}{3}, \frac{5}{6}$ and full. The cruise was primarily a survey with an ordinary vertically transmitting echo-sounder; at stations, Io miles apart, plankton nets were hauled from the bottom to the surface.

At each station, the following procedure was adopted for very roughly estimating the noise and reverberation level. The amplifier was set at $0, \frac{1}{6}, \frac{1}{3}$, $\frac{1}{2}, \frac{2}{3}, \frac{5}{6}$ and full, successively and at each setting, the machine was allowed to make a few transmissions on the $150 \mathrm{fm}$ range, when the ship was hove to on station. At each level of amplification, the paper record was marked to a certain distance in $\mathrm{mm}$ from the transmission mark; these distances were taken as indices of noise and reverberation. Each record was marked for measurement, when wet, so that there would then be no question of differential fading on different records. A typical record is shown in Fig. 2, giving three separate series of measurements, at $150 \mathrm{fm}$ range with the ship stopped, at $1500 \mathrm{fm}$ range with the ship stopped, and again at $150 \mathrm{fm}$ range, when the ship was under way. Thus each record gives a measure of the noise in $\mathrm{mm}$, when the sounder is transmitting horizontally beneath the sea surface.

The plankton at the surface was estimated with the use of the tin tow-net, or high-speed tow-net, hauled just below the surface for Io min as the ship steamed away from the station. This model (described by Gehringer, 1952) stands $7 \mathrm{ft}(213 \mathrm{~cm}$.) high, has a mouth opening of $40 \mathrm{~cm}$ in diameter, and has 
a metal net of 40 meshes to the linear inch. It was towed from a bracket on its dorsal surface with a light Larsson trawl warp from the boom; a Larsson depressor was slung underneath to stabilize it. Used in this way, it was exceedingly stable at all speeds.

The net was shot from the quarter as the ship steamed away from a station; as the ship accelerated, a little warp was let out until the net was visible between $5 \mathrm{fm}(9 \cdot \mathrm{Im})$ and the surface. After Io min the net was hauled in at full speed with no difficulty; the catch was washed out with a hose, bottled and preserved.

A

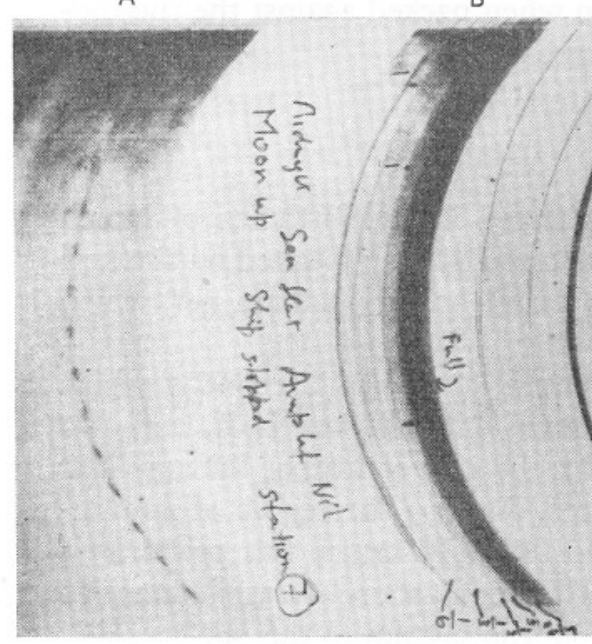

C

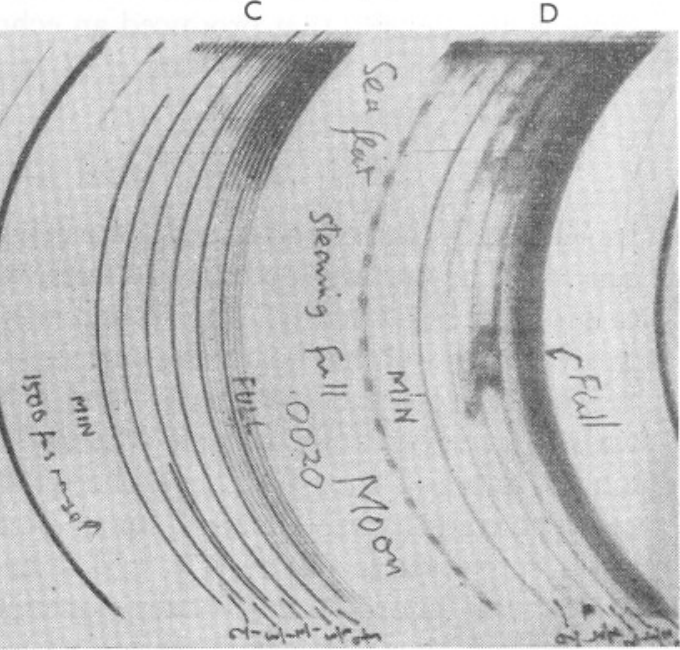

Fig. 2. An illustration of the methods used in estimating the noise levels on Platessa Cruise vIII, I953. A: part of the horizontal sounder trace, as the ship approached station 7 , amplifier setting $\frac{1}{3}$. B: transmisson records made at various amplifier settings, using the $150 \mathrm{fm}$ range scale. C: transmission records made at various amplifier settings, using $1500 \mathrm{fm}$ range scale. D: transmission records made at various amplifier settings, using the $150 \mathrm{fm}$ range scale, as Platessa was steaming away from the station. The echo at about $80 \mathrm{fm}$ in section $\mathrm{D}$ is from the ship's wake.

The plankton animals caught were identified as copepods, sagittae, euphausiids (Nyctiphanes couchii Bell), and fish larvae, and were expressed as numbers per Io min haul; the numbers of animals were multiplied by the cubes of their lengths to give an estimate of volume. A long series of measurements of the lengths of adults and copepodite stages of Calanus finmarchicus Gunner, Pseudocalanus elongatus Boeck, Paracalanus parvus Claus, and Temora longicornis Müller, was used for this purpose (Cushing, in press). Additional length measurements of Acartia, Oithona, Evadne, Sagitta, euphausiid furcilia, and smaller larvae were also made. The results were expressed as volumes of total zooplankton in $\mathrm{mm}^{3}$ and as volumes of euphausiids in $\mathrm{mm}^{3}$. 
Six observations were made on Platessa Cruise viII I953, during flat calm weather at night and during the day. Fifteen observations were made on Platessa Cruise IX I953, under a variety of conditions. The summarized results are set out in Table II, showing volumes of zooplankton in $\mathrm{mm}^{3}$ and the indices of noise in $\mathrm{mm}$; the state of the sea is also recorded. On Cruise viII, the degree of amplification was measured as described above, but on Cruise Ix, it was placed at a constant low setting, which was unrecorded.

Table II. Volumes of Zooplankton, IN $M^{3}$, Per io min Haul and INDICES OF NOISE, IN MM

\begin{tabular}{|c|c|c|c|c|}
\hline \multicolumn{5}{|c|}{ Platessa Cruise viII, I953 } \\
\hline Station & $\begin{array}{c}\text { Zooplankton } \\
\left(\mathrm{mm}^{3} \times \mathrm{IO}^{6}\right)\end{array}$ & $\begin{array}{l}\text { Euphausiids } \\
\left(\mathrm{mm}^{3} \times \mathrm{IO}^{6}\right)\end{array}$ & $\begin{array}{l}\text { Noise, in mm } \\
\text { gain } \frac{2}{3} \\
\text { I500 fm range }\end{array}$ & State of sea \\
\hline 8 & $\mathrm{I} \cdot 82$ & 0.02 & 6 & 0 \\
\hline 6 & $7 \cdot 35$ & $I \cdot 75$ & 27 & o \\
\hline 7 & 4.55 & $3 \cdot 13$ & $2 I$ & 0 \\
\hline 30 & $1 \cdot 90$ & 0.07 & 3.5 & $\circ$ \\
\hline $8 a$ & $0.4 \mathrm{I}$ & 0.002 & 5 & 0 \\
\hline I4 & 0.33 & 0.02 & 5 & $\circ$ \\
\hline \multicolumn{5}{|c|}{ Platessa Cruise Ix, I953 } \\
\hline Station & $\begin{array}{c}\text { Zooplankton } \\
\left(\mathrm{mm}^{3} \times 10^{6}\right)\end{array}$ & $\begin{array}{l}\text { Euphausiids } \\
\left(\mathrm{mm}^{3} \times 10^{6}\right)\end{array}$ & Noise in $\mathrm{mm}$ & State of sea \\
\hline 50 & $0.8 \mathrm{I}$ & 0.002 & $6 \cdot 5-7$ & 0 \\
\hline $50 a$ & 0.003 & 0.0 & $5-5 \cdot 5$ & 0 \\
\hline 51 & 0.68 & 0.001 & $7-7 \cdot 5$ & 0 \\
\hline $5 \mathrm{I} a$ & $I \cdot I 0$ & 0.01 & $5 \cdot 5$ & 0 \\
\hline $52 a$ & 0.80 & 0.002 & $7-7 \cdot 5$ & 2 \\
\hline 54 & 0.02 & 0.0 & $5-5 \cdot 5$ & 0 \\
\hline $54 a$ & I.47 & 0.04 & $2 \cdot 5-3$ & $I-2$ \\
\hline 55 & $I \cdot 25$ & 0.07 & $I \cdot 5$ & 0 \\
\hline 56 & $I \cdot 09$ & 0.01 & 4.5 & ० \\
\hline $6 I$ & $\mathrm{I} \cdot 7 \mathrm{I}$ & 0.10 & $4 \cdot 5-5$ & 0 \\
\hline 62 & 0.60 & 0.17 & 4 & 0 \\
\hline 63 & 0.21 & 0.12 & 6.5 & 2 \\
\hline 64 & I.03 & 0.01 & $5 \cdot 5-6$ & 3 \\
\hline 65 & $1 \cdot 30$ & 0.02 & $5 \cdot 5-6$ & $3-4$ \\
\hline 66 & 0.08 & 0.001 & 6.5 & $3-4$ \\
\hline
\end{tabular}

On Cruise virI the highest noise indices occurred when euphausiids were present in large numbers, dominating the whole plankton catch. On Cruise Ix, when the euphausiids, in general, comprised only a small part of the plankton catch, the noise indices were always about the same, there being no violent differences as there were on the previous cruise; in fact, the noise did not increase noticeably when the state of sea increased. Again the average volume of euphausiids on Cruise vIII was about twenty times that found on Cruise IX.

Fig. 3 illustrates the traces at stations 3 and 6 on Cruise virI. Fig. 3A shows the clear trace at station 3 on the $150 \mathrm{fm}$ range, with the amplifier set at $\frac{1}{3}$. Fig. $3 \mathrm{~B}$ shows the trace at station 6 on the $150 \mathrm{fm}$ range, with the amplifier set at $\frac{1}{3}$. The remarkable difference is attributed to a marked difference in quantity of zooplankton, in this case, mainly euphausiids. 

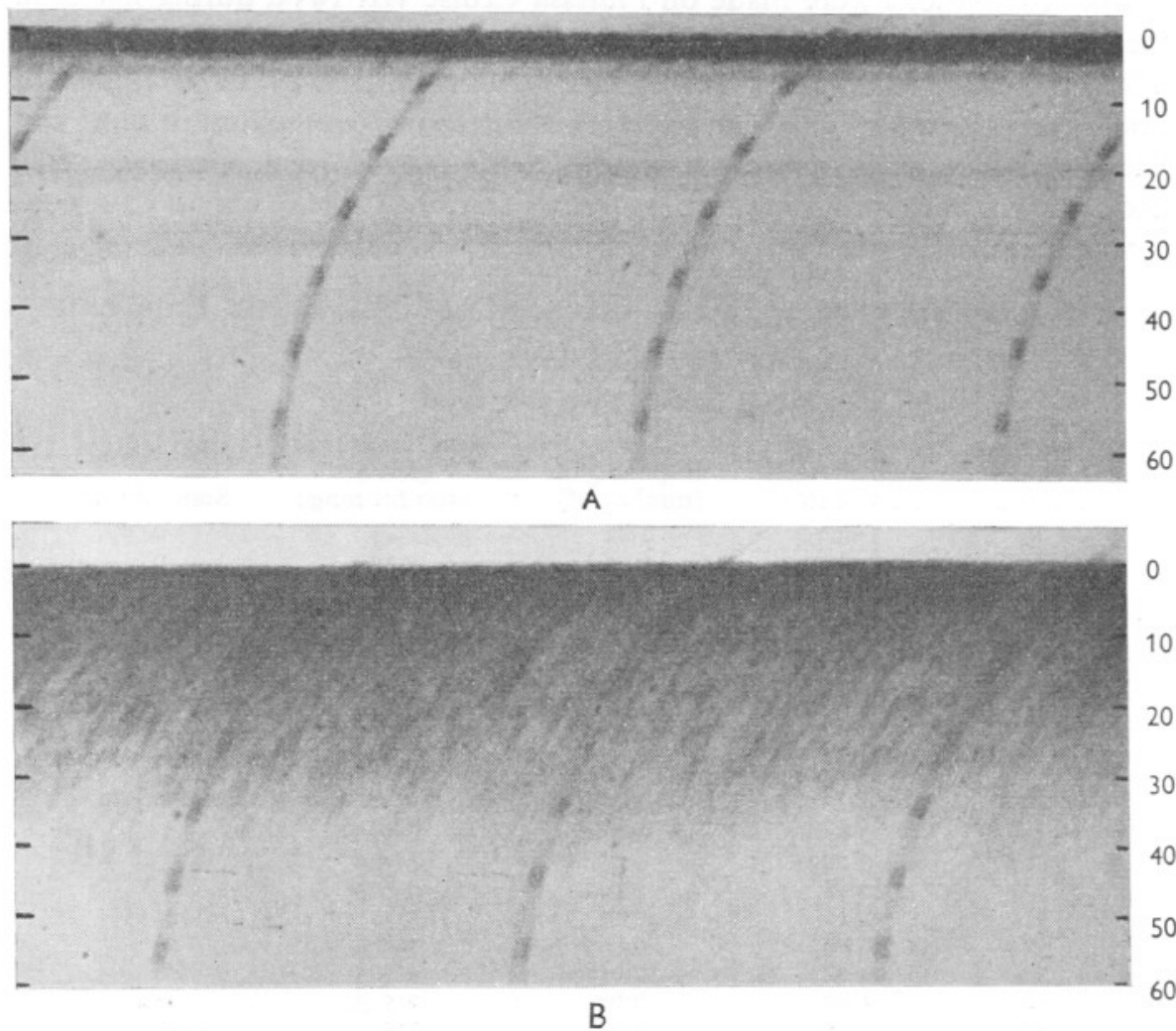

Fig. 3. The 'noisy' trace at night in the North Sea. Range in fathoms shown on right. A : part of the horizontal sounder trace observed 30 miles away from the plankton patches, in full daylight, at an amplifier setting of $\frac{1}{3}$. B: part of the horizontal sounder trace observed in the plankton patch at night, at an amplifier setting of $\frac{1}{3}$. Note the constant decrease in signal strength from the transmission outwards, with increasing range.

\section{Discussion}

The traces shown in Fig. I and in Fig. 3 are of a particular type. To describe it we must distinguish between noise and an echo. If an echo-sounder is switched on, but is not transmitting, the receiver is open to receive any sound of the frequency to which it is tuned; this is water noise. Again if the echosounder is transmitting, part of the transmitted energy is scattered by small particles, by irregularities in the temperature structure of the water and by irregularities on the bottom; some of this randomly scattered energy reaches the receiver as noise. This reverberation, as the scattering is sometimes called, is like the water noise in that it is random in character and appears as a record that is dirty all over. 
Now, when the amplifier of an echo-sounder is turned up progressively, the paper becomes marked irregularly all over, with water noise, reverberation and lastly with instrument noise. An echo is distinguished from noise by its consistent appearance at about the same depth or range in successive transmissions. It is only the successive transmissions that establish the identity of an echo, as opposed to noise. This is why a paper recorder is necessary for establishing the presence of signals from fish shoals on a CRT, because, on the screen, noise and echoes cannot readily be compared with signals of previous transmissions.

The traces shown in Figs. I and 3 have three characters: first they are horizontally extensive, secondly they are irregularly diffuse, and lastly, when the amplifier is turned up, they show increased range. If the amplifier was turned up whilst a fish trace was being observed, the trace darkened with increased intensity of received signal, but did not increase its apparent range. Again, a fish trace nearly always has a discrete character and is rarely diffuse (however, traces of herring at Sandettié sometimes appear somewhat diffuse at night).

When the traces of euphausiids in the North Sea are compared with those of copepods and cladocerans in Windermere, it is found that the quantity of material was not so very different. At stations 6 and 7 on Cruise vIII, there were between $\mathrm{I} \cdot 75$ and $3 \cdot 13 \times 10^{6} \mathrm{~mm}^{3}$ of euphausiids per Io min haul with the tin townet. If we assume that the net filters $233 \mathrm{~m}^{3}$ in Io min when towed at an average speed of 6 knots, then the comparable quantity of zooplankton in Windermere would have amounted to $6.5 \times 10^{6} \mathrm{~mm}^{3}$ per $233 \mathrm{~m}^{3}$. Here we have assumed that each copepod and cladoceran (some of which were small juveniles) occupied an average volume of $\mathrm{I} \mathrm{mm}^{3}$ (the length of Diatopmus gracilis was I. I28 mm, and that of adult of Daphnia hyalina was $\mathrm{I} \cdot 733 \mathrm{~mm}-$ the more common juveniles were $I \cdot 2 \mathrm{~mm}$; each value is the mean of fifty measurements). In the North Sea and in Windermere, the average plankton volume was Io $\mathrm{mm}^{3} / 1$. in the former and $28 \mathrm{~mm}^{3} / 1$. in the latter.

Another similarity between the two traces is that both are continuous from the transmission mark outwards. This is not in itself unusual, but the only other diffuse and extensive trace, the shallow scattering layer, composed of fish larvae, appears to stay at night far enough from the surface, to allow a clear gap to appear between the transmission mark and the trace itself. The density of pilchard larvae in the shallow scattering layer in the Western Channel amounted to $0 . \mathrm{II} / \mathrm{m}^{3}$ as caught (or between 0.5 and $\mathrm{I} / \mathrm{m}^{3}$ allowing for escape from the Petersen young-fish trawl: J. P. Bridger, private communication). If each fish larva was $8-\mathrm{I} 2 \mathrm{~mm}$ long, there would be about $\mathrm{I} \mathrm{mm}^{3} / 1$. The difference of ro to 28 times between this estimate and that for the noisy trace is attributed to the presence of air bladders (which were perhaps resonating) in the pilchard larvae, which would scatter sound much more efficiently than would plankton animals or bladderless fish larvae. 
When working in Windermere we were primarily interested in the thin echo layer associated with the thermocline. From our observations we associated the echo layer with the presence of plankton animals (Diaptomus gracilis and Daphnia hyalina) packed against it (Cushing et al., in press). When the echo layer occurred at Io $\mathrm{m}$, the signal was rather weak but quite discernible, and there were 28 animals/1., which was the same density as that found by night at the surface in Windermere. Between the two signals there was probably not a great deal of difference in strength. The transmitted signal at the depth of the plankton animals was reduced by many times, through being transmitted through Io $\mathrm{m}$ of water; hence, to produce a signal on the echo-sounder at all comparable, the animals must have been packed considerably more tightly than appears from the estimate of $28 / 1$. Since our samples were taken with a Rodhe bottle about $\frac{1}{2} \mathrm{~m}$ long, one of them could easily be composed of a thin layer of animals at a density of I $40 / 1$.

There are three types of echo trace that are perhaps associated with plankton: first, the shallow scattering layer of fish larvae; secondly, the echo layer at the thermocline; and thirdly, the noisy trace. The fourth type of record that has been associated with plankton is that from the deep scattering layer, which has been attributed partly to the presence of euphausiids. The noisy trace that was found in the North Sea is interesting from this point of view, in that it was possibly composed of euphausiids.

Before we discuss the noisy trace in relation to the deep scattering layer, it would be well to consider the numbers of euphausiids caught at Stations 6 and 7 on Platessa Cruise viII, 1953. To obtain a minimum estimate, it will be assumed that the tin townet filtered the water efficiently. The numbers of adult euphausiids caught in Io min at Stations 6 and 7 were I 5,900 and 28,500 respectively, which makes 68 and $\mathrm{I} 22 / \mathrm{m}^{3}$, if an average speed of 6 knots was maintained during the haul. If the net was only working at $20 \%$ efficiency, these figures must be raised by five times. Other reported catches are:

(I) Mackintosh (1934). The average numbers of Euphausia superba per haul is $\mathrm{I}, 000$, which is $\mathrm{I}-5 / \mathrm{m}^{3}$, assuming $20 \%$ efficiency. The highest catch was $190-950 / \mathrm{m}^{3}$.

(2) Hardy \& Gunther (1935), figs. 90, 92, 95, table 52. The highest numbers of Euphausia frigida, E. superba and Thysanoëssa spp. were up to $150 / \mathrm{m}^{3}$, assuming $20 \%$ efficiency.

(3) Einarsson (I945). Assuming $20 \%$ efficiency, the highest catch of Thysanoëssa longicaudata was $4-12 \cdot 5 / \mathrm{m}^{3}$.

(4) Moore (1950). Euphausia brevis. $\mathrm{I} \cdot 5 / \mathrm{m}^{3}$; by inference from luminescence observations at night, $7-15 / \mathrm{m}^{3}$.

(5) Boden (1950). E. pacifica; assuming $20 \%$ efficiency, the highest catch was $2 \cdot 5 / \mathrm{m}^{3}$.

(6) Glover (1952). E. krohnii, Meganyctiphanes norvegica, Nyctiphanes couchii, Thysanoëssa inermis, $T$. longicaudata; assuming perfect filtration with the plankton recorder, there were $\mathrm{I}-3 / \mathrm{m}^{3}$ (or $5-\mathrm{I} 5 / \mathrm{m}^{3}$, assuming $20 \%$ efficiency). 
It follows that the catches made in the North Sea in May were amongst the highest recorded. This might have been associated in part with the moon-light drawing the euphausiids to the surface, but it is also believed that an important factor was the use of the high-speed tin townet, which has a wide enough mouth to make escape at a towing speed of $6-8$ knots $(309-412 \mathrm{~cm} / \mathrm{sec})$ nearly impossible.

During these trials, euphausiids were found at a density in numbers of perhaps $\mathrm{I} 2 \mathrm{O} / \mathrm{m}^{3}$, yet signals in the noisy trace were not recorded from beyond $30-80 \mathrm{fm}\left(55^{-1} 46 \mathrm{~m}\right)$ range; the nature of the trace and the character of our observations, continuously for $3 \mathrm{~h}$ over 20 miles of sea, do not lead us to suspect that there was a boundary to euphausiid distribution running parallel to the ship's course at a range of $80 \mathrm{fm}$ (I46 m).

In our North Sea observations euphausiids did not give a signal beyond $80 \mathrm{fm}$ ( $146 \mathrm{~m}$ ) depth, whereas the deep scattering layer was recorded down to $450 \mathrm{fm}(823 \mathrm{~m})$. There is evidently a difference here of a large order of magnitude, which might be either instrumental or biological. It is difficult to believe that our machine was very much less sensitive than those used in studies on the deep scattering layer because the relatively high figure of $\mathrm{I} k \mathrm{~kW}$ was put into the transducer although the pulse length was short; so the signal-to-noise ratio was lower than if a longer pulse had been used. To our minds, our observations present yet another reason for doubting that that layer is due to euphausiids.

\section{SUMMARY}

An echo trace attributable to plankton organisms has been described. Its diagnostic character is that when the amplifier of the echo-sounder is turned up, the trace extends in range; a fish trace would not extend in range but would darken with increased intensity of signal.

This trace was observed at night in Windermere where it was possibly composed of copepods and cladocerans at a density of about 28 animals/1.; it was also observed at night in the North Sea, where it was probably composed of euphausiids at a density of 0.12 animals $/ 1$.

The euphausiids were caught with a high-speed townet, with a mouth opening of $40 \mathrm{~cm}$ diameter. A very rough comparison was made between the North Sea trace of euphausiids and the signal that comes from the deep scattering layer, which may be partly composed of euphausiids.

\section{REFERENCES}

Boden, B. P., 1950. Plankton organisms in the deep scattering layer. U.S. Navy Electronics Lab., San Diego, Calif., Rep. 186, 29 pp.

Burd, A. C. \& LeE, A. J., I95I. The sonic scattering layer in the sea. Nature, Lond., Vol. I67, pp. 624-6.

Cushing, D. H. Production and a pelagic fishery. Fish. Invest., Lond., Ser. 2. (In the Press.) 
Cushing, D. H., Lee, A. J. \& Richardson, I. D. Echo traces associated with thermoclines. (In the Press.)

EInARsson, H., 1945. Euphausiacea, I. Northern Atlantic Species. Dana Rep., Vol. 5, No. 27, I85 pp.

GeHRINGER, J. W., I952. An all-metal plankton sampler (Model Gulf III). Spec. sci. Rep. U.S. Fish Wildl. Serv., No. 88, pp. 7-I2.

GLOVER, R. S., I952. Continuous plankton records: The Euphausiacea of the Northeastern Atlantic and the North Sea, 1946-48. Hull Bull. Mar. Ecol., Vol. 3, pp. I85-2I4.

HARDY, A. C. \& GuntheR, E. R., I935. The plankton of the South Georgia whaling grounds and adjacent waters, I926-1927. 'Discovery' Rep., Vol. II, 456 pp.

Hersey, J. B. \& BACKUS, R. H., I954. New evidence that migrating gas bubbles, probably the swimbladders of fish, are largely responsible for scattering layers on the continental rise south of New England. Deep-Sea Res., Vol. I, pp. I90.

Hersey, J. B. \& MOORE, H. B., I948. Progress report on scattering layer observations in the Atlantic Ocean. Trans. Amer. Geophys. Union, Vol. 29, pp. 34I-54.

Hersey, J. B., Johnson, H. R. \& Davis, L. C., I952. Recent findings about the deep scattering layer. F. Mar. Res., Vol. Ir, pp. I-9.

Mackintosh, N. A., I934. Distribution of the macroplankton in the Atlantic section of the Antarctic. 'Discovery' Rep., Vol. 9, pp. 65-160.

Marshall, N. B., I95I. Bathypelagic fishes as sound scatterers in the ocean. F. Mar. Res., Vol. I0, pp. I-I7.

MOORE, H. B., I950. The relation between the scattering layer and the Euphausiacea. Biol. Bull., Woods Hole, Vol. 99, pp. I8I-2I2.

TUCKER, G. H., I95I. Relation of fishes and other organisms to the scattering of underwater sound. F. Mar. Res., Vol. 10, pp. 215-38. 